\title{
PENGARUH BUDAYA PERUSAHAAN DAN KEPEMIMPINAN TRANSFORMASIONAL DALAM MENENTUKAN KEBERHASILAN IMPLEMENTASI ERP
}

\author{
Kosasih \\ Program Studi Magister Manajemen, Fakultas Ekonomi, Universitas Negri Jakarta \\ e-mail: kosasih@gmail.com
}

\begin{abstract}
ABSTRAK
Penelitian ini bertujuan untuk mengetahui pengaruh budaya perusahaan dan kepemimpinan transformasional terhadap keberhasilan implementasi ERP. Penelitian dilakukan di sebuah perusahaan komponen elektronik di Bekasi untuk membuktikan pengaruh antar variabel dengan menggunakan kuesioner sebagai alat pengumpulan data dari responden yang berjumlah 200 orang. Pengujian instrumen data dilakukan dengan menggunakan uji validitas dan realibilitas. Sedangkan untuk menguji konstruk hubungan antar variable digunakan metode pengujian Structural Equation Model (SEM) dengan aplikasi Lisrel. Hasil penelitian dapat disimpulkan sebagai berikut: terdapat pengaruh kepemimpinan transformasional terhadap implementasi ERP dengan koefisien korelasi sebesar 0.60, dan juga terdapat pengaruh budaya perusahaan terhadap implementasi ERP dengan koefisien korelasi sebesar 0.47 .
\end{abstract}

Kata kunci:Kepemimpinan Transformasional, Budaya Perusahaan, Implementasi ERP, Structural Equation Model (SEM).

\begin{abstract}
This study aims to determine the influence of corporate culture and transformational leadership on the successful implementation of ERP. The study was conducted in an electronic components company in Bekasi to prove the influence between variables using a questionnaire as a means of collecting data from 200 respondents. Testing instrument data is done using validity and reliability. As for test constructs relationships between variables used testing method of Structural Equation Model (SEM) with lisrel application. The results of the study can be summarized as follows: there is the influence of transformational leadership on ERP implementation with a correlation coefficient of 0.60, and also there is the influence of corporate culture on ERP implementation with a correlation coefficient of 0:47.
\end{abstract}

Keywords: Transformational Leadership, Corporate Culture, ERP Implementation, Structural Equation Model (SEM).

\section{PENDAHULUAN}

Proses globalisasi yang dimulai dengan penandatangan kesepakatan perdagangan internasional GATT (General Agreement on Tariff and Trade) di kota Marrakesh, Maroko pada bulan April 1994 telah membawa nuansa baru yang sangat signifikan terhadap perkembangan bisnis di seluruh dunia.

Dampak integrasi aktivitas bisnis global terhadap aktivitas bisnis di suatu negara, terjadi melalui tiga mekanisme, yakni: tekanan perdagangan yang semakin kompetitif, produksi multinasional dan integrasi pasar keuangan. Semakin menajamnya kompetisi bisnis antar perusahaan merupakan merupakan komponen utama dalam pembahasan isu dampak globalisasi ini. Hanya perusahaan-perusahaan yang efisien yang selamat dalam kompetisi, dan hal ini hanya akan mungkin jika perusahaan memiliki performa kerja yang unggul [1].
Perkembangan dunia bisnis yang semakin kompetitif ini memaksa perusahaan untuk bersaing, tidak hanya dalam hal persaingan produksi, pemasaran dan pengelolaan sumber daya manusia saja, tapi juga dalam hal penanganan transaksi antara perusahaan secara internal maupun eksternal.

Berdasarkan hasil penelitian yang dilakukan Batada dan Rahman menyimpulkan, bahwa implementasi ERP yang terpadu akan berdampak positif pada kemampuan operasional perusahaan dalam menghasilkan keuntungan secara financial [2]. Hasil penelitian lainnya yang dilakukan oleh Hamilton dan Asundi melaporkan hasil penelitiannya bahwa dalam penerapan ERP di perusahaan kecil dan menengah, terdapat peningkatan dalam penjualan dan percepatan inventory setelah implementasi ERP di perusahaan tersebut [3]. 
Menurut Sumner bahwa Enterprise Resources Planning (ERP) merupakan sebuah sistem yang menyediakan database perusahaan dimana seluruh transaksi bisnis dimasukkan, diproses, dimonitor, dan dilaporkan [4].

\section{Enterprise Resources Planning (ERP)}

Sistem Enterprise Resource Planning (ERP) adalah "core software programs used by companies to integrate and coordinate information in every area of the business" [5]. Enterprise Resource Planning sebagai sebuah alat manajemen yang menyeimbangkan permintaan dan pasokan, mengandung kemampuan untuk menghubungkan pelanggan dan pemasok menjadi rantai pasokan yang lengkap. ERP menggunakan proses bisnis untuk pengambilan keputusan, dan memberikan integrasi lintas-fungsional antara penjualan, pemasaran, manufaktur, operasi, logistik, pembelian, keuangan, pengembangan produk baru, dan sumber daya manusia. ERP memungkinkan bisnis dijalankan dengan layanan pelanggan dan produktivitas tingkat tinggi dengan biaya rendah [6].

Secara umum, tahapan sistem Enterprise Resource Planning (ERP) meliputi tahapan perencanaan, tahapan analisis, tahapan desain, tahapan dukungan teknis, dan tahapan implementasi [7]. Faktor kunci keberhasilan ERP pada tahap sebelum implementasi adalah: tahap persiapan proyek, tahap pemilihan teknologi, tahap formulasi proyek, kualitas pelayanan vendor/konsultan dan tahap implementasi [8]. Beberapa faktor eksternal yang mendorong perusahaan untuk mengimplementasikan ERP adalah kebijakan pemerintah, kebijakan perbankan dan issu politik [9].

Berdasarkan beberapa teori tentang ERP di atas, dapat disimpulkan bahwa ERP adalah sebuah aplikasi perangkat lunak komputer yang digunakan oleh manajemen dalam melakukan koordinasi dan integrasi informasi antar lintas fungsi untuk mencapai efisiensi dan efektivitas pencapaian tujuan strategik perusahaan.

\section{Budaya Perusahaan}

Budaya perusahaan adalah " $a$ set of values, beliefs, and norms of behavior shared by members of a firm that influences individual employee preferences and behaviors" [10]. Budaya perusahaan juga didefinisikan sebagai seperangkat perilaku, perasaan, dan kerangka psikologis yang terinternalisasi sangat mendalam dan dimiliki oleh anggota korporasi [11]. Budaya perusahaan juga didefinisikan sebagai "A system of shared meanings and common beliefs held by corporate members that determines, in a large degree, how they act towards each other" [12].

Budaya perusahaan merupakan paradigma manajemen yang dapat meningkatkan kinerja. Bila korporasi tidak memiliki nilai-nilai yang diyakininya, korporasi cenderung memasrahkan dirinya pada nasib, dan sulit untuk mencapai tujuan yang dikehendakinya. Nilai-nilai yang telah diyakini oleh kebanyakan anggota korporasi sebagai suatu aturan main yang sah membuat nilai-nilai itu menjadi budaya. Budaya yang datang dari bawah, disamping mudah terbentuk, akan lebih kuat untuk menunjang keberhasilan korporasi dalam mencapai misi dan strateginya [13]. Demikian pula secara dimensi, budaya organisasi memiliki hubungan positif yang signifikan terhadap kinerja manajerial secara praktis [14].

Berdasarkan teori-teori tentang budaya perusahaan tersebut di atas, dapat diambil kesimpulan bahwa budaya perusahaan adalah sistem nilai, keyakinan, norma, serta kebiasaan yang menjadi pedoman dan panutan untuk mengarahkan perilaku setiap anggota-anggota dalam korporasi, agar dalam bekerja dapat bersama-sama untuk mencapai sasaran yang tertuang dalam visi, misi dan tujuan korporasi.

\section{Kepemimpinan Transformasional}

Teori Neo Charismatic adalah teori-teori kepemimpinan terbaru yang menekankan simbolisme, daya tarik emosional, dan komitmen pengikut yang luar biasa. Teori-teori yang termasuk ke dalam teori ini adalah Teori Kepemimpinan Karismatik (Charismatic Leadership), Teori Kepemimpinan Transaksional (Transactional Leadership), Teori Kepemimpinan Transformasional (Transformational Leadership), dan Teori Kepemimpinan Visioner (Visionary 
Leadership). Burn mendeskripsikan bahwa transformational leadership adalah "a process in which leaders and followers raise one another to higher levels of morality and motivation" [15]. Yaitu merupakan sebuah proses dimana pemimpin dan bawahan mengembangkan satu sama lain tingkat moralitas dan motivasi yang tinggi. Mengembangkan satu sama lain tingkat moralitas dan motivasi yang tinggi.

Seorang pemimpin yang transformasional adalah " $a$ person who displays or creates charismatic leadership, inspirational leadership, intelectual stimulation, and a feeling that each individual follower counts" [16]. Dapat diartikan bahwa seorang pemimpin tranformasional adalah seseorang yang menciptakan kepemimpinan kharismatik, kepemimpinan yang penuh inspirasi, stimulasi intelektual dan perasaan bahwa semua bawahan harus diperhitungkan. Bass juga menjelaskan bahwa pemimpin akan mampu mendorong semangat, menggunakan nilai-nilai, kepercayaan dan dapat memenuhi kebutuhan para bawahannya. Pemimpin yang melakukan hal itu dalam situasi yang cepat berubah atau dalam situasi yang krisis disebut dengan pempimpin transformasional.

Berdasarkan pemaparan-pemaparan di atas, pada intinya teori kepemimpinan transformasional adalah konsep kepemimpinan yang menekankan pentingnya peranan pemimpin dalam menginspirasi dan memotivasi anggotanya untuk melakukan perubahan kinerja organisasi.

Berdasarkan pemaparan dalam latar belakang masalah di atas, maka identifikasi dari beberapa masalah yang terjadi di PT AEMI, yaitu kurang efektifnya implementasi ERP sehingga koordinasi dan kerjasama antar lintas departemen masih lemah. Selain itu, kepedulian pimpinan departemen terhadap implementasi masih rendah. Hal-hal tersebut mengakibatkan perencanaan produksi yang tidak sesuai permintaan customer, jumlah inventory yang tinggi, laporan-laporan kinerja departemen terlambat dan ketidaksesuaian data antar laporan departemen.

Dari sekian banyak hal-hal yang memengaruhi implementasi ERP sesuai identifikasi masalah di atas, maka batasan masalah dalam penelitian ini adalah pada variabel-variabel independen penelitian, yaitu: kepemimpinan transformasinal para pimpinan di PT AEMI; budaya perusahaan di PT AEMI; dan implementasi ERP di PT AEMI.

Berdasarkan hal-hal yang telah dikemukakan di atas, maka penelitian dilakukan dengan meneliti bagaimana proses penerapan ERP, bagaimana kepemimpinan transformasional dan bagaimana budaya perusahaan di PT AEMI.

Tujuan yang akan dicapai dalam penelitian ini, sesuai dengan perumusan masalah adalah sebagai berikut: (1) Menguji pengaruh kepemimpinan transformasional terhadap implementasi ERP di PT AEMI (2) Menguji pengaruh budaya perusahaan terhadap implementasi ERP di PT AEMI.

\section{Hasil Penelitian Yang Relevan}

Hasil penelitian-penelitian terdahulu yang relevan dengan penelitian ini dapat dirangkum seperti pada Tabel 1 .

\section{Kerangka Teoritik}

Dalam kerangka teoritik ini dijelaskan keterkaitan antara masing-masing variabel yang sedang diteliti sehingga akan menghasilkan keterkaitan antar konsep-konsep dari variabelvariabel yang diuji. Hubungan keterkaitan antar variabel digambarkan berdasarkan hasil penelitian-penelitian sebelumnya, sehingga dapat dijadikan dasar untuk menentukan hipotesis dalam penelitian ini.

Berdasarkan hasil penelitian Ijaz, Malik, Lodhi, Habiba dan Irfan ditemukan bahwa terdapat beberapa penentu kesuksesan penerapan ERP yaitu kepemimpinan dalam tim, keterlibatan dan komitmen manajemen dalam proses implementasi ERP [17]. Hal ini di dukung oleh penelitian lain oleh Tripalguna yang menyatakan bahwa peranan manajemen puncak mengandung banyak variabel di dalamnya [18]. Dukungan lain tentang masalah ini juga dinyatakan oleh Tripalguna bahwa kepemimpinan yang kuat dan komitmen yang dimiliki oleh manajemen puncak perusahaan merupakan suatu keharusan juka ingin mensukseskan implementasi ERP [19]. 
Tabel 1. Penelitian Terdahulu.

\begin{tabular}{|c|c|c|c|}
\hline No & Peneliti & Judul Penelitian & Kesimpulan \\
\hline 1 & $\begin{array}{l}\text { Dezdar \& Ainin } \\
\text { (2012) }\end{array}$ & $\begin{array}{l}\text { Investigating the Impact of } \\
\text { Organizational Culture on Enterprise } \\
\text { Resource Planning \& Implementation } \\
\text { Project }\end{array}$ & $\begin{array}{l}\text { Penelitian ini mengkonfirmasi ulang bahwa } \\
\text { budaya perusahaan memiliki hubungan positip } \\
\text { dengan keberhasilan implementasi ERP. }\end{array}$ \\
\hline 2 & $\begin{array}{l}\text { Ahmad Rabai } \\
\text { (2009) }\end{array}$ & $\begin{array}{l}\text { ERP Systems Implementation and } \\
\text { Organizational Culture: The Case of } \\
\text { Jordan, }\end{array}$ & $\begin{array}{l}\text { Peneltian menyimpulkan bahwa terdapat } \\
\text { hubungan antara budaya perusahaan dan } \\
\text { penerapan ERP. }\end{array}$ \\
\hline 3 & $\begin{array}{l}\text { Yuanyuan Guo, } \\
\text { Yuqiang Feng \& } \\
\text { Chaoyou Wang } \\
\text { (2014) }\end{array}$ & $\begin{array}{l}\text { The impact mechanism of } \\
\text { organizational culture on ERP } \\
\text { assimilation: a multi-case study. }\end{array}$ & $\begin{array}{l}\text { Penelitian menyimpulkan bahwa ada pengaruh } \\
\text { budaya internal dan eksternal korporasi dalam } \\
\text { proses asimilasi ERP dengan melibatkan } \\
\text { keikutsertaan pada user dalam proses tersebut }\end{array}$ \\
\hline 4 & $\begin{array}{l}\text { Mwika, D., } \\
\text { Christopher } \\
\text { Chembe dan } \\
\text { Douglas Kunda } \\
\text { (2014) }\end{array}$ & $\begin{array}{l}\text { Comparative Study of Cultural } \\
\text { Differences Of Success Factors Of } \\
\text { Erp Implementation In Developed } \\
\text { And Emerging Economies: Case } \\
\text { Study Of Norway And Zambia } \\
\end{array}$ & $\begin{array}{l}\text { Penelitian ini mengkaji faktor-faktor keberhasilan } \\
\text { ERP yang terpengaruh dari efek kebudayaan } \\
\text { nasional di Norwegia dan Zambia. Hasilnya } \\
\text { menunjukkan identifikasi dimensi budaya } \\
\text { memiliki pengaruh yang besar terhadap ERP }\end{array}$ \\
\hline 5 & $\begin{array}{l}\text { Mir, et. al. } \\
\text { (2014) }\end{array}$ & $\begin{array}{l}\text { Effect of Organizational Culture and } \\
\text { Top Management Support On ERP } \\
\text { Implementation }\end{array}$ & $\begin{array}{l}\text { Penelitian ini menguji pengaruh top management } \\
\& \text { organizational culture terhadap ERP. Hasil } \\
\text { penelitian menunjukkan bahwa organizational } \\
\text { culture dan top management berpengaruh } \\
\text { langsung terhadap ERP baik secara individu } \\
\text { maupun secara bersamaan }\end{array}$ \\
\hline 6 & $\begin{array}{l}\text { Zhen Shao, } \\
\text { Yuqiang feng } \\
\text { dan Qing Hu } \\
\text { (2013) }\end{array}$ & $\begin{array}{l}\text { The impact mechanism of } \\
\text { transformational } \\
\text { leadership style on exploitative and } \\
\text { exploratory } \\
\text { learning of ERP systems }\end{array}$ & $\begin{array}{l}\text { Hasil penelitian ini menyimpulkan bahwa } \\
\text { transformational leadership memiliki hubungan } \\
\text { positif terhadap penerapan ERP dalam hal } \\
\text { keterbukaan dan partisipasi pada proses } \\
\text { pembentukan budaya pembelajaran pengambilan } \\
\text { keputusan }\end{array}$ \\
\hline 7 & $\begin{array}{l}\text { Amir Ijaz, et. Al. } \\
\text { (2014) }\end{array}$ & $\begin{array}{l}\text { A Qualitative Study of the Critical } \\
\text { Success Factors of ERP System - A } \\
\text { Case Study Approach }\end{array}$ & $\begin{array}{l}\text { Terdapat beberapa penentu kesuksesan penerapan } \\
\text { ERP yaitu kepemimpinan dalam tim, keterlibatan } \\
\text { dan komitmen manajemen dalam proses } \\
\text { implementasi ERP }\end{array}$ \\
\hline 8 & $\begin{array}{l}\text { Afzaal H. Seyal } \\
\text { dan Mohd Noah } \\
\text { Abd. Rahman } \\
\text { (2014) }\end{array}$ & $\begin{array}{l}\text { Testing Bass \& Avolio Model of } \\
\text { Leadership in Understanding ERP } \\
\text { Implementation among Bruneian } \\
\text { SMEs }\end{array}$ & $\begin{array}{l}\text { Pimpinan puncak dengan gaya kepemipinan } \\
\text { transformational leadership memiliki pengaruh } \\
\text { yang signifikan terhadap penerapan ERP }\end{array}$ \\
\hline 9 & $\begin{array}{l}\text { Nyoman A. } \\
\text { Tripalguna } \\
\text { (2012) }\end{array}$ & $\begin{array}{l}\text { Peran Budaya perusahaan: Studi } \\
\text { Ekplorasi pada PT. SIMOPLAS }\end{array}$ & $\begin{array}{l}\text { Kepemimpinan yang kuat dan komitmen yang } \\
\text { dimiliki oleh manajemen puncak perusahaan } \\
\text { merupakan suatu keharusan jika ingin } \\
\text { mensukseskan implementasi ERP }\end{array}$ \\
\hline 10 & $\begin{array}{l}\text { Christian Leyh } \\
\text { (2014) }\end{array}$ & $\begin{array}{l}\text { Critical Success Factors for ERP } \\
\text { Projects in Small and Medium-sized } \\
\text { Enterprises - The Perspective of } \\
\text { Selected German SMEs }\end{array}$ & $\begin{array}{l}\text { Dalam implementasi ERP, dukungan manajemen } \\
\text { puncak memainkan peran utama sebagai faktor } \\
\text { terpenting dalam keberhasilan ERP }\end{array}$ \\
\hline
\end{tabular}

Penelitian sebelumnya oleh Leyh telah menunjukkan bahwa dalam implementasi ERP, dukungan manajemen puncak memainkan peran utama sebagai faktor terpenting dalam keberhasilan ERP [20]. Berdasarkan hasil penelitian-penelitian yang telah dilakukan sebelumnya tersebut, dapat ditarik sebuah kesimpulan bahwa kepemimpinan manajemen puncak adalah salah satu faktor penentu kesuksesan implementasi ERP.
Hipotesis 1: Kepemimpinan transformasional memiliki pengaruh positif langsung terhadap Implementasi ERP

Sudah banyak yang melakukan studi dilakukan terkait hubungan antara budaya perusahaan dengan implementasi ERP. Salah satunya adalah penelitian yang dilakukan Dezdar dan Ainin yang menyimpulkan bahwa terdapat hubungan yang signifikan antara budaya perusahaan dan implementasi ERP. 
Berdasarkan hasil studi ini budaya perusahaan memiliki peranan penting dalam implementasi ERP, karena organisasi harus menghentikan pola kerja yang selama ini dijalankan [21].

Berdasarkan hasi penelItian lainnya, Rabaai menyimpulkan bahwa terdapat hubungan antara budaya perusahaan dan penerapan ERP. Hasil studi tersebut menyarankan korporasi menyederhanakan struktur hirarki, mengurangi rantai birokrasi dan melakukan konsesus dalam pengambilan keputusan agar dapat mempercepat pengambilan keputusan [22]. Pada penelitian Guo, Feng dan Wang juga ditemukan bahwa ada pengaruh budaya internal dan eksternal korporasi dalam proses asimilasi ERP dengan melibatkan keikutsertaan pada user dalam proses tersebut [24]. Studi tersebut menyarankan budaya inovasi yang melibatkan user akan berpengaruh terhadap hasil asimilasi ERP. Berdasarkan penelitian-penelitian tersebut dapat ditarik sebuah hipotesis sebagai berikut:

Hipotesis 2: Budaya perusahaan memiliki pengaruh positif langsung terhadap Implementasi ERP

\section{Hipotesis Penelitian}

Dengan menggunakan penelitian kuantitatif asosiatif, maka digunakan model analisis SEM dengan model hipotesa seperti pada Gambar 1.

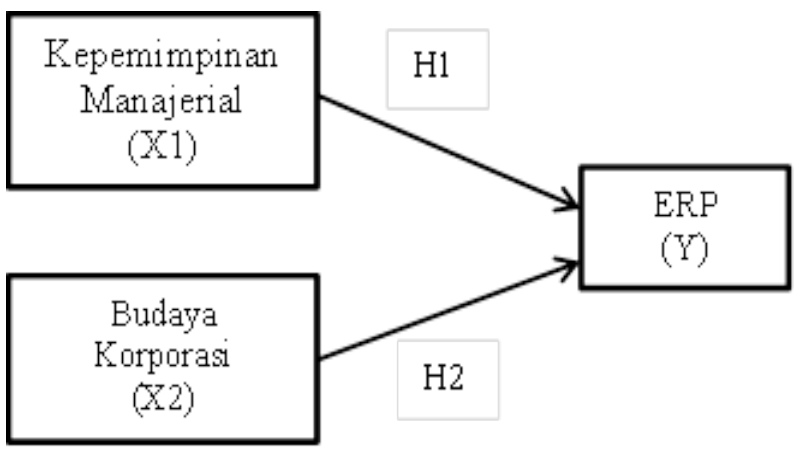

Gambar 1. Model Hipotesa Penelitian

Hipotesis penelitian yang dibangun berdasarkan model SEM di atas adalah sebagai berikut:

Hipotesis 1 : Kepemimpinan transformasional berpengaruh terhadap implementasi ERP;
Hipotesis 2 : Budaya perusahaan berpengaruh terhadap implementasi ERP;

\section{METODE PENELITIAN}

Lokasi penelitian dilakukan di PT AEMI yang berada di Kawasan Industri Marunda Centre, Tarumajaya, Bekasi, Jawa Barat. Waktu yang digunakan selama penelitian adalah mulai bulan Oktober-2015 sampai dengan Februari2016.

Penelitian ini merupakan penelitian pengujian korelasional antar variabel-variabel (terikat dan bebas) yang diuji dengan melakukan pengujian hipotesa. Variabel terikat adalah implementasi ERP, serta variabelvariabel bebas adalah kepemimpinan transformasional dan budaya perusahaan. Melalui pengujian korelasional tersebut akan diketahui seberapa kuat pengaruh antar variabel yang diuji.

Populasi penelitian terdiri dari populasi sebanyak 216 orang, sedangkan pengambilan sample sebanyak 200 orang yang diyakini dapat mewakili populasi. Ukuran sampel dihitung dengan = (n) $\mathrm{x} 5$ observasi untuk setiap estimated parameter [24]. Teknik pengumpulan data dilakukan dengan menggunakan instrumen berbentuk kuesioner yang disebarkan kepada karyawan di dalam lingkungan PT AEMI.

Definisi yang terukur yang dilengkapi dengan rincian indikator penelitian (terukur) atas variabel-variabel yang diuji sebagai berikut:

Indikator dimensi kepemimpinan transformasional adalah sebagai berikut: raits (motives, personality, values), Confidence and optimism, Skills \& expertise, Behavior, Integrity (honesty, behavior consistent with value), Influence tactics, dan Attributions about follower [25].

Indikator dimensi budaya perusahaan adalah: Involvement, Cosistency, dan Mission [26].

Indikator implementasi ERP adalah: System quality, Information quality, Individual impact, Workgroup impact dan Organizational impact [27].

Jenis instrumen yang digunakan untuk pengambilan data adalah dengan metode kuesioner berdasarkan skala Likert. Skala 
Likert, yaitu skala yang menggunakan 5 pilihan jawaban responden. Kelima itu adalah: Sangat setuju (SS), Setuju (S), Netral (N), Tidak Setuju (TS), dan Sangat Tidak Setuju (STS). Sebelum dilakukan pengujian confirmatory factor analysis, maka dilakukan pengujian validitas dan reliabilitas. Dalam penelitian ini menggunakan alat analisa Structural Equation Modeling (SEM) dengan menggunakan program LISREL.

\section{Hipotesis Statistika}

Hipotesis statistik yang menggambarkan pernyataan tentang karakteristik populasi yang merupakan jawaban sementara atas pertanyaan penelitian dapat dinyatakan sebagai berikut:

Hipotesis 1 : Kepemimpinan transformasional berpengaruh terhadap implementasi ERP.

$\mathrm{H} 0: \beta_{\mathrm{Y} 1} \leq 0$

$\mathrm{H} 1: \beta_{\mathrm{Y} 1}>0$

Hipotesis 2 : Budaya perusahaan berpengaruh terhadap implementasi ERP

$\mathrm{H} 0: \beta_{\mathrm{Y} 2} \leq 0$

$\mathrm{H} 1: \beta_{\mathrm{Y} 2}>0$

\section{HASIL DAN PEMBAHASAN Analisis Uji Validitas}

Berdasarkan tabel hasil uji validitas dapat disimpulkan bahwa untuk butir-butir pertanyaan dari variabel kepemimpinan transformasional yang valid dimana $r$ hitungnya lebih besar dari 0,138 adalah: KM2, KM3, KM4, KM5 dan KM7. Sedangkan butir-butir pertanyaan kepemimpinan transformasional yang tidak valid, dimana $r$ hitungnya lebih kecil dari 0,138 adalah: KM1 dan KM6, sehingga pertanyaanpertanyaan tersebut tidak digunakan. Untuk butir-butir pertanyaan dari variabel budaya perusahaan semuanya menunjukkan valid, sehingga tidak ada butir-butir pertanyaan yang perlu dibuang atau diganti.

Untuk butir-butir pertanyaan dari variabel implementasi ERP yang valid, dimana $r$ hitungnya lebih besar dari 0,138 adalah: ER3, ER4, ER5, ER6, ER7, ER8 dan ER9. Sedangkan butir-butir pertanyaan implementasi ERP yang tidak valid, di mana $r$ hitungnya lebih kecil dari 0,138 adalah: ER1, ER2 dan ER10, sehingga pertanyaan-pertanyaan tersebut tidak digunakan.

\section{Analisis Uji Reliabilitas}

Berdasarkan hasil uji realibilitas menggunakan SPSS versi 22 atas pertanyaanpertanyaan tersebut didapatkan hasil nilai Alpha Cronbach sebagai berikut:

Tabel 2. Hasil Uji Reliabilitas

\begin{tabular}{lcc}
\hline & $\begin{array}{c}\text { Cronbach } \\
\text { Alpha } \\
\text { Awal }\end{array}$ & $\begin{array}{c}\text { Cronbach } \\
\text { Alpha } \\
\text { Awal }\end{array}$ \\
\hline Keubah Laten & 0,549 & 0,639 \\
Budaya Korporasi & 0,725 & 0,725 \\
Implementasi ERP & 0,496 & 0,572 \\
Kinerja Korporasi & 0,693 & 0,705 \\
\hline
\end{tabular}

Hasil analisis dalam penelitian ini menunjukkan bahwa untuk variabel kepemimpinan transformasional, instrumen yang digunakan sebagai indikator variabel tersebut pada perhitungan awal memiliki nilai Alpha Cronbach sebesar 0,549. Setelah butirbutir pertanyaan yang tidak valid (KM1 dan KM6) dibuang, maka nilai Alpha Cronbach naik menjadi 0,639 sehingga dapat disimpulkan bahwa instrumen yang digunakan sebagai indikator variabel kepemimpinan sudah reliabel atau handal.

Untuk variabel budaya perusahaan, instrumen yang digunakan sebagai indikator variabel tersebut memiliki nilai Alpha Cronbach sebesar 0,725, jauh berada di atas 0,50. Dengan demikian dapat disimpulkan bahwa, instrumen yang digunakan sebagai indikator variabel budaya perusahaan sudah reliabel.

Untuk variabel implementasi ERP, instrumen yang digunakan sebagai indikator variabel tersebut pada perhitungan awal memiliki nilai Alpha Cronbach sebesar 0,496. Setelah butir-butir pertanyaan yang tidak valid (ER1, ER2 dan ER10) dibuang, maka nilai Alpha Cronbach menjadi 0,572 sehingga variabel implementasi ERP berada di atas 0,50. Dengan demikian dapat disimpulkan bahwa instrumen yang digunakan sebagai indikator variabel implementasi ERP sudah reliabel. 


\section{Pengujian Confirmatory Factor Analysis (CFA)}

Pengujian CFA bertujuan untuk menganalisa keterkaitan atau saling hubungan antar variabel-variabel yang diteliti. Pengujian CFA pada penelitian ini menggunakan aplikasi Lisrel versi 8.3 dengan hasil pengujian sebagai berikut:

Berdasarkan diagram output hasil pengujian CFA dapat disimpulkan bahwa untuk variabel kepemimpinan transformasional, semua indikator-indikator yang valid memiliki t-hitung di atas 1,96. Oleh karena itu, pada tahap selanjutnya semua indikator tersebut disertakan dalam pengujian model.

Variabel budaya perusahaan, semua indikator-indikator yang valid memiliki t-hitung di atas 1,96. Oleh karena itu, pada tahap selanjutnya semua indikator disertakan dalam pengujian model. Hal ini juga sejalan dengan hasil uji validitas yang sudah dilakukan sebelumnya, di mana seluruh pertanyaan indikator-indikator variabel budaya perusahaan valid semua.

Sedangkan untuk variabel implementasi ERP, semua indikator valid memiliki t-hitung di atas 1,96. Oleh karena itu, pada tahap selanjutnya semua indikator tersebut disertakan dalam pengujian model.

\section{Pengujian Model}

Terhadap implementasi ERP, perhitungan koefisien kepemimpinan transformasional $=0,6$ dan budaya perusahaan $=0,47$.

Berdasarkan hasil perhitungan koefisien tersebut dapat dirumuskan persamaan model yang dihasilkan atas pengujian SEM terhadap variabel-variabel amatan sebagai berikut: Implementasi $\mathrm{ERP}=0,60 \mathrm{x}$ kepemimpinan transformasional $+0,47 \times$ budaya perusahaan, di mana, Errorvar =0,31 dan $\mathrm{R}^{2}=0,69$.

Artinya, nilai R-square 69\% menunjukkan bahwa hanya 69\% keragaman implementasi
ERP yang dapat dijelaskan oleh faktor kepemimpinan transformasional dan budaya perusahaan. Sedangkan faktor-faktor sisanya sebesar 31\% dijelaskan oleh faktor-faktor lain.

\section{Pengujian Hipotesis}

Pengujian hipotesis untuk setiap hipotesis dapat dilihat pada Tabel 3.

Dari Tabel 3, kedua hipotesis yang diajukan dalam penelitian ini (H1, dan H2) diterima dengan penjelasan sebagai berikut: nilai t-tabel adalah 1,96 dimana jumlah sampel $>100$ dan derajat kepercayaan $\alpha=0,05$. Apabila t-hitung lebih kecil dari t-tabel $(1,96)$, maka $\mathrm{H}_{0}$ ditolak dan $\mathrm{H}_{1}$ diterima. Pengujian thitung atas kedua hipotesis secara lengkap adalah: (1) hasil perhitungan statistik uji dan hasil pengujian hipotesis 1 bahwa nilai t-hitung sebesar 18,36. Nilai t-hitung ini $>$ t-tabel 1,96 sehingga berada di area penolakan $\mathrm{H}_{0}$, maka $\mathrm{H}_{1}$ diterima. Dengan demikian dapat disimpulkan bahwa, terdapat pengaruh signifikan budaya perusahaan terhadap implementasi ERP. (2) Hasil perhitungan statistik uji dan hasil pengujian hipotesis 2 bahwa nilai t-hitung sebesar 18,79. Nilai t-hitung ini > t-tabel 1,96 sehingga berada di area penolakan $\mathrm{H}_{0}$, maka $\mathrm{H}_{1}$ diterima. Dengan demikian dapat disimpulkan bahwa, terdapat pengaruh signifikan kepemimpinan transformasional terhadap implementasi ERP.

Berdasarkan hasil pengujian, beberapa hipotesis yang teruji adalah sebagai berikut: Hipotesis 1 bahwa budaya perusahaan berpengaruh terhadap implementasi ERP. Berdasarkan hasil pengujian hipotesis dalam penelitian ini terbukti bahwa budaya perusahaan berpengaruh signifikan terhadap implementasi ERP. Hasil pengujian ini mendukung hasil-hasil penelitian sebelumnya yang telah dilakukan oleh Dezdar dan Aini, Rabai, Shao, Feng dan $\mathrm{Hu}$, Mwika dan Kunda dan Mir, et. al. [21,22,28-31]. Berdasarkan pengamatan secara

Tabel 3 Hasil Pengujian Hipotesis

\begin{tabular}{llccl}
\hline & \multicolumn{1}{c}{ Hipotesis } & t-hitung & Keputusan & \multicolumn{1}{c}{ Keterangan } \\
\hline $\mathrm{H}_{1}$ & $\begin{array}{l}\text { Kepemimpinan manajerial } \\
\text { berpengaruh positif terhadap } \\
\text { implementasi ERP }\end{array}$ & 18,79 & Terima $\mathrm{H}_{\mathrm{a}}$ & $\begin{array}{l}\text { Kepemimpinan manajerial Signifikan } \\
\text { berpengaruh positif terhadap } \\
\text { implementasi }\end{array}$ \\
\hline $\mathrm{H}_{2}$ & $\begin{array}{l}\text { Budaya korporasi berpengaruh positif } \\
\text { terhadap implementasi ERP }\end{array}$ & 18,36 & Terima $\mathrm{H}_{\mathrm{a}}$ & $\begin{array}{l}\text { Budaya korporasi signifikan berpengaruh } \\
\text { positif terhadap implementasi ERP }\end{array}$ \\
\hline
\end{tabular}


empiris di dalam perusahaan, pembentukan budaya perusahaan sangat memengaruhi keberhasilan ERP. Implementasi modul-modul ERP baru bisa dijalankan setelah sebelumnya dibuat prosedur dan instruksi kerja serta dilakukan dengan cara manual. Sehingga pada saat implementasi ERP, perilaku dan langkahlangkah pekerjaan pengguna ERP tidak mengalami perubahan yang cukup drastis. Hipotesis 2 bahwa kepemimpinan transformasional berpengaruh terhadap implementasi ERP. Berdasarkan hasil pengujian hipotesis dalam penelitian ini terbukti bahwa budaya perusahaan berpengaruh signifikan terhadap implementasi ERP. Hasil pengujian ini mendukung hasil-hasil penelitian sebelumnya yang telah dilakukan oleh Sao, Feng dan $\mathrm{Hu}$, Ijaz et. al., Seyal dan Rahman, Tripalguna dan Leyh [17,18,20,28,32]. Berdasarkan pengamatan secara empiris di dalam perusahaan, kepemimpinan transformasional sangat berpengaruh dalam implementasi ERP. Hal ini dapat dipahami, karena implementasi ERP mengharuskan pengguna untuk merubah kebiasaan dan perilaku lama dari manual menuju sistem terintegrasi, sehingga banyak menghadapi kendala dan resistensi dari pengguna ERP. Pada beberapa departemen yang memiliki kepemimpinan transformasional yang baik, implementasi ERP dapat lebih cepat. Para pemimpinnya dapat memberikan motivasi dan pengarahan, sehingga karyawan lebih terpacu untuk menyelesaikan implementasi ERP.

\section{KESIMPULAN}

Beberapa kesimpulan yang merupakan hasil dari pengujian dan pembahasan dalam penelitian ini adalah sebagai berikut: hasil pengujian menunjukkan bahwa terdapat pengaruh kepemimpinan transformasional (X2) terhadap keberhasilan implementasi ERP (Y) di PT AEMI dengan tingkat koefisien sebesar 0,60. Artinya, jika nilai kepemimpinan transformasional meningkat sebesar 1 dan nilai variabel lainnya tetap, maka akan meningkatkan nilai implementasi ERP sebesar 0,60. Hasil pengujian menunjukkan bahwa terdapat pengaruh budaya perusahaan (X1) terhadap keberhasilan implementasi ERP (Y) di PT
AEMI dengan tingkat koefisien sebesar 0,47. Artinya, adalah jika nilai budaya perusahaan meningkat sebesar 1 dan nilai variabel lainnya tetap, maka akan meningkatkan nilai implementasi ERP sebesar 0,47.

\section{DAFTAR PUSTAKA}

[1]. Geoffrey Garrett, 2000, "The Cause of Globalization,"Journal of Comparative Political Studies, Vol. 33 (6/7), August/September, hh. 941-991

[2]. Imran Batada dan Asmita Rahman, 2012, "Measuring System Performance \& User Satisfaction after Implementation of ERP”, Proceedings of Informing Science \& IT Education Conference (InSITE).

[3]. Hamilton L.C. dan R. Asundi, 2008, "Technology Usage and Innovation: It's Effect on the Profitability of SMEs," Management Research News, Vol 31 (11), hh. 830-845.

[4]. Mary Sumner, 2005, Enterprise Resources Planning, $1^{\text {st }}$ Ed. (New Jersey: Pearson Prentice Hall), h.2.

[5]. Monk E., \& Wagner B., 2013, Concept in Enterprise Resource Planning. $4^{\text {th }}$ Ed. U.S.A.: Cengage Learning, h.1

[6]. Wallace T. F., \& Kremzar M. H., 2001, ERP: Making It Happen: The Implementers' Guide to Success with Enterprise Resource Planning. New Jersey. U.S.A: John Wiley \& Son Inc. h5.

[7]. Santo F Wijaya \& Suparto Danudiarto, 2009, ERP dan Solusi Bisnis, (Yogyakarta: Graha Ilmu, Ed.1). h. 65

[8]. Abdesamad Zouine dan Pierre Fenies, 2014, "The Critical Success Factors of The ERP System Project: A MetaAnalysis Methodology". The Journal of Applied Business Research, September/ Oktober, h.1410

[9]. Gede Rasben Dantes dan Zainal Arifin Hasibuan, 2011, "The Impact of ERP System Implementation on Organization: case study ERP Implementation in Indonesia”, IBAMA Business Review, Vol. 2011, Article ID 210664, 10 pages, DOI:10.5171/2011.210664. h.9. 
[10]. Besanko, D., D. Dranove, and M. Shanley, 2000, Economics of Strategy (2nd Ed.), John Wiley and Sons, Inc.

[11]. David Osborne and Peter Plastrik, 2006, Banishing Bureaucracy: The Five Strategies for Reinventing Government, second edition (Essex, Ma.: Osborne and Plastrik), hh.75-90.

[12]. Stephen P. Robbins, and Mary Coulter, 2007, Management. $9^{\text {th }}$ Ed. Prentice Hall.

[13]. Rumengan, RJ, 2002, Budaya Organisasional: "Paradigma Manajemen Yang Melejitkan Kinerja," Usahawan, No.06/th.XXXI/Juni

[14]. Mashal Ahmed \& Saima Shafiq. 2014, "The Impact of Organizational Culture on Organizational Performance: A Case Study of Telecom Sector”. Global Journal of Management and Business Research. Volume 14 Issue 3 Version 1.

[15]. Burns, J. M., 1978, Leadership. New York: Harper \& Row, h. 203

[16]. Bass, B., 1999, "Two Decades of Research and Development in Transformational Leadershi"p. European Journal of Work and Organizational Psychology, 8(1),hh. 9- 32.

[17]. Amir Ijaz, et.al., 2014, “A Qualitative Study of the Critical Success Factors of ERP System-A Case Study Approac"h, Proceedings of the 2014 International Conference on Industrial Engineering and Operations Management, January 7 - 9.

[18]. Tripalguna, Nyoman A., 2012, Pengaruh Peranan Manajemen Puncak Terhadap Kesuksesan Implementasi ERP, Universitas Indonesia, h.88

[19]. Ibid.

[20]. Christian Leyh, 2014, “Critical Success Factors for ERP Projects in Small and Medium-sized Enterprises-The Perspective of Selected German SMEs". Proceedings of the 2014 Federated Conference on Computer Science and Information Systems hh. 1181-1190

[21]. Dezdar, op. cit. hh. 1125-1133.

[22]. Rabaai, loc.cit.

[23]. Yuanyuan Guo, Yuqiang Feng \& Chaoyou Wang, 2014, "The impact mechanism of organizational culture on ERP assimilation: a multi-case study", Hawaii International Conference on System Science, $47^{\text {th }}$.

[24]. Anderson, J.F. Hair, R.E., Tatham, R.L. and Black, W.C., 1998, Multivariate Data Analysis. Upper Saddle River, Prentice Hall.

[25]. Gary Yukl, 2008, Leadership in Organization. (New Jersey: Prentice Hall: Seventh Ed.). h. 12

[26]. Ibid.

[27]. Ifinedo, P., 2006, Extending the Gable dkk. Enterprise Systems Success measurement model: a preliminary study. Journal of Information Technology Management, Vol.17, No. 1, H.14-33.

[28]. Shao, Zhen, Yuqiang Feng dan Qing Hu, 2013, The impact mechanism of transformational leadership style on exploitative and exploratory learning of ERP systems.

[29]. Mwika, D., Chembe, C. \& Kunda, D., 2014, "Comparative Study of Cultural Differences of Success Factors Of Erp Implementation In Developed And Emerging Economies: Case Study of Norway And Zambia". International Journal of Computer Engineering \& Technology (IJCET). Volume 5, Issue 8, August.

[30]. Mwika, D., Chembe, C. \& Kunda, D, 2014, "Comparative Study of Cultural Differences of Success Factors Of Erp Implementation In Developed And Emerging Economies: Case Study of Norway And Zambia". International Journal of Computer Engineering \& Technology (IJCET). Volume 5, Issue 8, August.

[31]. Mir et.al., 2014, "Effect of Organizational Culture and Top Management Support on ERP Implementation". Institute of Business Administration, University of the Punjab. Sci.Int. (Lahore), 26(3), 1361.

[32]. Seyal, Afzaal H. dan Mohd Noah Abd. Rahman, 2014, Testing Bass \& Avolio Model of Leadership in Understanding ERP Implementation among Bruneian SMEs, 2014. 